FRIEDRICH KLAGES

Lehrbuch der organischen Chemie II 


\title{
LEHRBUCH \\ DER ORGANISCHEN CHEMIE
}

\author{
IN DREI B ÄNDEN
}

VON

DR. FRIEDRICH KLAGES

Professor der organischen Chemie an der Universität München

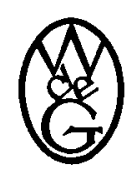

1962

WALTER DE GRUYTER \& CO.

vormals G. J. Göschen'sche Verlagshandlung • J. Guttentag, Verlagsbuchhandlung

Georg Reimer - Karl J. Trübner - Veit \& Comp. 


\title{
LEHRBUCH \\ DER ORGANISCHEN CHEMIE
}

\author{
II. BAND \\ THEORETISCHE UND ALLGEMEINE ORGANISCHE CHEMIE
}

VON

DR. FRIEDRICH KLAGES

Professor der organischen Ghemie an der Universität München

3., völlig neubearbeitete Auflage

MIT 145 ABBILDUNGEN UND 40 TABELLEN

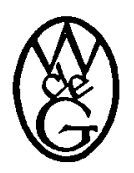

1962

WALTER DE GRUYTER\& CO.

vormals G. J. Göschen'sche Verlagshandlung • J. Guttentag, Verlagsbuchhandlung

Georg Reimer - Karl J. Trübner - Veit \& Comp.

BERLIN 
Copyright 1962 by Walter de Gruyter \& Co., vormals G. J. Göschen'sche Verlagghandlung, J. Guttentag, Veriagsbuchhandlung, Georg Reimer, Karl J. Trübner, Veit \& Comp., Berlin W 30. - Alle Rechte, auch die des auszugsweisen Nachdrucks, der photomechanischen Wiedergabe, der Herstellung von Mikrofilmen und der Übersetzung, vorbehalten. - Archiv-Nr. 5294621. - Printed in Germany. Satz und Druck: Walter de Gruyter \& Co., Berlin W 30 
Dem Andenken meines hochverehrten Lehrers

Herrn Geh. Regierungsrat, Prof. Dr. phil.,

Dr. ing. e. h., Dr. med. h. c., Dr. phil. h. c.

HEINRICH WIELAN D

in Dankbarkeit zugeeignet 
